\title{
PENGARUH PERCEIVED USEFULNESS DAN PERCEIVED EASE OF USE TERHADAP BEHAVIORAL INTENTION DENGAN PENDEKATAN TECHNOLOGY ACCEPTANCE MODEL (TAM) PADA PENGGUNA INSTANT MESSAGING LINE DI INDONESIA
}

\author{
Ricky Aditya ${ }^{1}$, Aditya Wardhana ${ }^{2}$ \\ Administrasi Bisnis, Fakultas Komunikasi dan Bisnis, Universitas Telkom \\ e-mail: RickyAdityaaaa@gmail.com \\ e-mail: Aditya.telkomuniversity@gmail.com
}

\begin{abstract}
Among a variety of instant messaging that now exist, LINE is one instant messaging that is interesting to study with the rapid growth of users and its superiority compared to WhatsApp and Blackberry. The aim of this study was to determine the influence of perceived usefulness and perceived ease of use on behavioral intention on LINE instant messaging users in Indonesia. This research is quantitative descriptive data and causal analysis, respondents surveyed in this study amounted to 400 users instant messaging LINE in Indonesia with incidental sampling technique.The results showed that perceived usefulness in the position of $75.81 \%$ with a number of high category, perceived ease of use are at the $81.43 \%$ figure with a high category, behavioral intention is in a position $79.52 \%$ with high category, perceived usefulness significant effect against behavioral intention amounted to $18.83 \%$, perceived ease of use significantly influence the behavioral intention amounted to $36.84 \%$ and the perceived usefulness and perceived ease of use significantly influence behavioral intention amounted to $55.7 \%$.
\end{abstract}

Keywords: Instant Messaging LINE, Perceived Usefulness, Perceived Ease of Use, Behavioral Intention

http://dx.doi.org/10.20885/jsb.vol20.iss1.art3

\begin{abstract}
Abstrak
Di antara berbagai instant messaging yang kini ada, LINE merupakan salah satu instant messaging yang menarik untuk diteliti dengan pesatnya pertumbuhan pengguna dan keunggulannya dibanding WhatsApp dan Blackberry. Tujuan dari penelitian ini adalah untuk mengetahui pengaruh perceived usefulness dan perceived ease of use terhadap behavioral intention pada pengguna instant messaging LINE di Indonesia. Penelitian ini merupakan penelitian kuantitatif dengan analisis data deskriptif dan kausal, responden yang diteliti dalam penelitian ini berjumlah 400 pengguna instant messaging LINE di Indonesia dengan teknik sampling insidental. Hasil penelitian menunjukan bahwa perceived usefulness berada pada posisi angka $75,81 \%$ dengan kategori tinggi, perceived ease of use berada pada posisi angka 81,43\% dengan kategori tinggi, behavioral intention berada pada posisi 79,52\% dengan kategori tinggi, perceived usefulness berpengaruh signifikan terhadap behavioral intention sebesar $18,83 \%$, perveived ease of use berpengaruh signifikan terhadap behavioral intention sebesar $36,84 \%$ serta perceived usefulness dan perceived ease of use berpengaruh signifikan terhadap behavioral inteniton sebesar 55,7\%.
\end{abstract}

Kata Kunci: Instant Messaging LINE, Perceived Usefulness, Perceived Ease of Use, Behavioral Intention

\section{PENDAHULUAN}

Salah satu fenomena yang menarik dari perkembangan Teknologi, Informasi dan Komunikasi (TIK) adalah kehadiran internet sebagai media baru yang tidak dapat dipisahkan dari kehidupan masyarakat modern saat ini. Media baru seperti internet merupakan media yang dapat menggeser media tradisional seperti 
televisi dan radiokarena media baru bersifat interaktif sehingga banyak diminati oleh banyak orang. Data hasil survey Asosiasi Penyelenggara Jasa Internet Indonesia menunjukan bahwa hingga akhir 2014 pengguna intenet di Indonesia berjumlah 88,1 juta jiwa (Riset Puskakom dan APJII, 2015).

Semakin pesatnya perkembangan internet merubah cara masyarakat untuk berkomunikasi yang lebih cepat dan real time. Instant Messaging (IM) saat ini mengalami perkembangan yang cukup pesat pada jaringan user karena kemampuannya mengirimkan pesan secara singkat dan cepat antara pengguna jasa telekomunikasi (Zuliarso dan Henry, 2013). Diantara berbagai instant messaging yang kini ada, LINE merupakan salah satu instant messaging yang menarik untuk diteliti. Hal tersebut juga dilatarbelakangi oleh beberapa alasan yang kuat untuk mengeksekusi penelitian ini.

Sejak dikeluarkan pada tahun 2011 hingga tanggal 4 April 2014, LINE mengalami pertumbuhan yang cepat hingga mencapai 400 juta pengguna di dunia (linecorp.com). sejalan dengan perkembangan tersebut, pengguna LINE di Indonesia saat ini telah mencapai 30 juta pengguna, setelah Jepang menduduki posisi puncak dengan 52 juta pengguna dan Thailand sebanyak 27 juta pengguna. Hal ini adalah capaian dari tersedianya karakteristik fitur dan layanan instant messaging LINE di setiap negara yang berbeda karena LINE selalu melakukan local approach (swa.co.id). Nielsen pada Agustus 2015 melakukan survey mengenai 10 aplikasi yang paling banyak dipilih di Indonesia. Hasilnya menyatakan bahwa Blackberry Messenger, LINE dan WhatsApp merupakan tiga aplikasi yang paling disukai (www.nielsen.com).

Sejalan dengan perkembangan instant messaging LINE dan fiturnya, Davis (1989) memaparkan bahwa ada dua sebab orang menerima dan menolak aplikasi teknologi informasi. Sebab yang pertama, orang cenderung menggunakan atau tidak menggunakan teknologi informasi karena mereka percaya bahwa teknologi informasi mampu membantu/mempersulit dalam melakukan tugastugas dengan lebih baik. Kedua, pengguna potensial percaya bahwa sistem ini berguna, namun pada saat yang sama mereka juga mempercayai bahwa sistem ini terlalu sulit digunakan. Variabel ini disebut sebagai perceived ease of use (Rustiana, 2006; Nysveen, Pedersen, dan Thorbjørnsen, 2005a, b).

Menariknya LINE untuk diteliti juga disebabkan oleh kemudahan yang diakomodir LINE bagi para penggunanaya sehingga bisa berkirim pesaninstant lebih cepat dan real time. Kemudahan yang akan didapat oleh pengguna tersebut menunjukan bahwa LINE berusaha memberikan manfaat yang lebih dibandingkan instant messaging lain yang sama-sama menyediakan platform instant messaging. LINE Indonesia kini sudah menjelma menjadi sebuah platform Life yang di dalamnya memiliki fitur-fitur pendukung kehidupan mulai dari games, sticker, Find Alumni, camera B612 dan LINE toss (swa.co.id). Variabel kemudahan ini dapat disebut sebagai perceived easy of use (Nysveen et al, 2005a, b ).

Peneliti melakukan survey awal terhadap 30 pengguna smartphone terkait Perceived Usefulness dan Perceived Ease of Use yang menggambarkan pencapaian dan kendala Instant Messaging LINE. Hasil survey tersebut menyatakan bahwa perceived usefulness pada instant messaging LINE mengalami kendala terkait fitur tambahan LINE seperti games, sticker, timeline, dan LINE Official Account dengan presentase sebesar $44,67 \%$. Begitu juga dengan perceivedease of use, penggun amengalami kendala terkait fitur tambahan LINE seperti games, sticker, timeline, dan LINE Official Accountdengan presentase sebesar 34\%. Peslak (2008) dalam penelitiannya mengenai instant messaging behavior, menyatakan bahwa perceived usefulness dan perceived ease of use signifikan berpengaruh terhadap intention to use instant messaging.

Namun, berdasarkan survey Nielsen pada tahun 2014 dengan responden pengguna smartphone di Indonesia, hasilnya menyatakan bahwa BBM masih menjadi aplikasi yang diminati (79\%). Kemudian WhatsApp (57 \%) dan LINE (37\%) mengikuti di bawahnya. Angka tersebut menunjukan pengguna smartphone di Indonesia masih mengandalakan BBM dibanding aplikasi sejenis untuk mengobrol dengan sesama. Hal ini sejalan dengan hasil survey awal peneliti terhadap 30 responden terkait minat perilaku (behavioral intention). Mereka menyatakan bahwa instant messaging LINE mengalami kendala terbesar 
terkait fitur tambahan LINE (Games, Sticker, Timeline, LINE Official Account) sehingga hanya $34,7 \%$ yang berniat menggunakan instant messaging LINE. Berdasarkan uraian di atas yang menjelaskan perceived usefulness dan perceived ease of use terhadap behavioral intention dengan pendekatan Technology Acceptance Model (TAM) merupakan suatu hal yang menarik untuk diteliti.

\section{KAJIAN PUSTAKA}

\section{Internet}

Secara umum, internet merupakan jaringan komputer global yang menghubungkan jutaan computer seluruh dunia (Rasul, 2008:3). Internet sering dinyatakan sebagai saluran yang efisien untuk penelitian, hiburan, pendidikan, dan e-commerce (Chau, Cole, Massey, Montoya-Weiss, dan O'Keefe, 2002) serta untuk komunikasi interpersonal (Cumming, Butler, dan Kraut, 2002). Teo, Lim, dan Lai (1999) menyatakan bahwa niat menggunakan internet dibentuk oleh kegunaan yang dipersepsikan, kesenangan yang dipersepsikan (secara langsung) dan kemudahan yang dipersepsikan (secara tidak langsung).

\section{Content Marketing}

Content Marketing adalah pendekatan pemasaran strategis yang berfokus pada menciptakan dan mendistribusikan konten yang bernilai, relevan dan konsisten untuk menarik dan mempertahankan secara jelas audience yang dituju dan pada akhirnya untuk mendorong customer melakukan tindakan yang menguntungkan (Content Marketing Institute, 2014). Content Marketing (Gunelius, 2011:10) meliputi semua bentuk content yang menambahkan nilai kepada consumer, mempromosikan bisnis, merek, produk atau jasa secara langsung ataupun tidak langsung. Rowley (2008) menyatakan bahwa konsep pemasaran konten sudah sampai pada generasi digital yang merupakan bagian penting dari lanskap komersial.

\section{Instant Messaging}

Zhou dan Lu (2011) menyatakan bahwa Instant Messaging (IM) merupakan layanan mobile populer yang memungkinkan pengguna untuk melakukan interaksi di manapun dengan teman/orang lain. IM memiliki fungsi-fungsi menarik seperti percakapan berbasis teks dan ikon as text chat and ikon ekspresi wajah.

Lewis dan Fabos (2005) menyatakan bahwa subjek sosial yang berkaitan dengan IM mengharapkan akses untuk terhubung ke teman-teman hanya dengan menekan tombol dan mengharapkan untuk membaca dan menulis dalam cara-cara tertentu yang mengarah pada pemenuhan hubungan dengan teman-teman. Selain itu, IM sebagai aplikasi berbasis internet juga menawarkan komunikasi yang real-time antar pengguna (Lou, 2005)

\section{Technology Acceptance Model}

Model penerimaan teknologi atau Technology Acceptance Model (TAM) merupakan salah satu model penerimaan pengguna terhadap penggunaan sistem teknologi informasi (Venkatesh, 2003). Technology Acceptance Model (TAM) diusulkan oleh Davis (1989) yang merupakan pengembangan dari teori-teori keperilakuan seperti Theory of Reasoned Action (TRA) oleh Fishbein dan Ajzen (1975) dan Theory of Planned Behaviour (TPB) oleh Ajzen (1991). TAM menjelaskan hubungan sebab akibat antara keyakinan (akan manfaat suatu teknologi/sistem informasi dan kemudahan penggunannya) dan perilaku, serta tujuan/keperluandan penggunaan aktual dari teknologi/sistem informasi tersebut (Davis, 1993).

\section{Perceived Usefulness}

Menurut Davis (1989) kemanfaatan (usefulness) adalah tingkat kepercayaan seseorang bahwa penggunaan sebuah sistem khusus akan meningkatkan performa pekerjaannya. Perceived usefulness didefinisikan sebagai daya guna suatu teknologi sehingga apabila daya guna suatu teknologi diragukan, tidak akan muncul intensi seseorang untuk menggunakannya.

\section{Perceived Ease of Use}

Menurut Davis (1989) kemudahan penggunaan yang dipersepsikan (perceived ease of use) didefinisikan sebagai sejauh mana seseorang percaya bahwa menggunakan suatu teknologi akan bebas dari usaha. Persepsi kemudahan penggunaan didasarkan pada sejauh mana calon pengguna mengharapkan sistem baru yang akan digunakan terbebas dari kesulitan. 


\section{Behavioral Intention}

Menurut Agarwal and Karahanna (2000) minat perilaku (behavioral intention) adalah suatu keinginan (minat) sesorang untuk melakukan suatu perilaku yang tertentu. Seseorang akan melakukan suatu perilaku (behavior) jika mempunyai keinginan atau minat (behavioral intention) untuk melakukannya. Minat juga dapat mengindikasikan dilakukannya suatu perilaku di masa depan dan mengulangnya di kemudian hari. Hasil penelitian sebelumnya menunjukan bahwa minat perilaku (behavioral intention) merupakan prediksi yang baik dari penggunaan teknologi oleh pemakai sistem. Selain itu, terdapat korelasi yang kuatantaraniat berperilaku dan perilaku yang sebenarnya (Vijayasarathy, 2003).

\section{Hubungan Perceived Usefulness, Perceived Ease of Use dan Behavioral Intention}

Teo et al. (1999) menyatakan bahwa perceived ease of use berpengaruh secara langsung dan tidak langsung (melalui variabel perceived usefulnes) dan perceived usefulnes berpengaruh langsung pada penggunaan layanan internet. Sejalan dengan penelitian tersebut, Nysveen et al. (2005a, b) juga menyatakan bahwa faktor pendukung dalam niat konsumen untuk menggunakan sebuah layanan mobile, adalah perceived usefulnes dan perceived ease of use. Kedua faktor tersebut merupakan faktor pendorong ekstrinsik yang merujuk pada imbalan atau tercapainya suatu target. Seseorang akan memiliki behavioral intention terhadap suatu teknologi jika ia memiliki perceived usefulnes dan perceived easy of use pada teknologi tersebut. Begitu juga sebaliknya. Berdasarkan teori dan kerangka pemikiran di atas, maka dibuat hipotesis sebagai berikut:
H1: Perceived Usefulness dan Perceived Ease of Use berpengaruh signifikan terhadap Behavioral Intention pada Pengguna Instant Messaging LINE di Indonesia.

$\mathrm{H} 2$ : Perceived Usefulness berpengaruh signifikan terhadap Behavioral Intention pada Pengguna Instant Messaging LINE di Indonesia.

H3: Perceived Ease of Use berpengaruh signifikan terhadap Behavioral Intention pada Pengguna Instant Messaging LINE di Indonesia.

\section{METODE PENELITIAN}

Populasi penelitian adalah pengguna instant messaging LINE di Indonesia. Penelitian ini dapat ditentukan melalui formula slovin. Peneliti menggunakan toleransi kesalahan $(e)$ sebesar 5\% dan jumlah populasi sebesar 30 juta penguna LINE di Indonesia (dailysocial.id). Berdasarkan hasil perhitungan tersebut, dapat diketahui bahwa sampel dalam penelitian ini berjumlah 400. Pengambilan sampel dalam penelitian ini dilakukan dengan nonprobability sampling. Teknik pengambilan sampel dalam penelitian ini menggunakan sampling incidental.

Analisis data penelitian ini menggunakan teknik analisis deskriptif dan analisis regresi berganda. Persamaan analisis regresi berganda yang digunakan dalam penelitian ini adalah:

$$
\mathrm{Y}=\alpha+\beta_{1} \mathrm{X}_{1}+\beta_{2} \mathrm{X}_{2}
$$

\footnotetext{
Keterangan:

$\mathrm{Y}=$ Behavioral Intention pengguna LINE di Indonesia

$\alpha=$ konstanta

$\beta=$ koefisien regresi

$\mathrm{X}_{1}=$ variabel bebas Perceived Usefulness

$\mathrm{X}_{2}=$ variabel bebas Perceived Ease of Use
}

\section{Model Kerangka Penelitian}

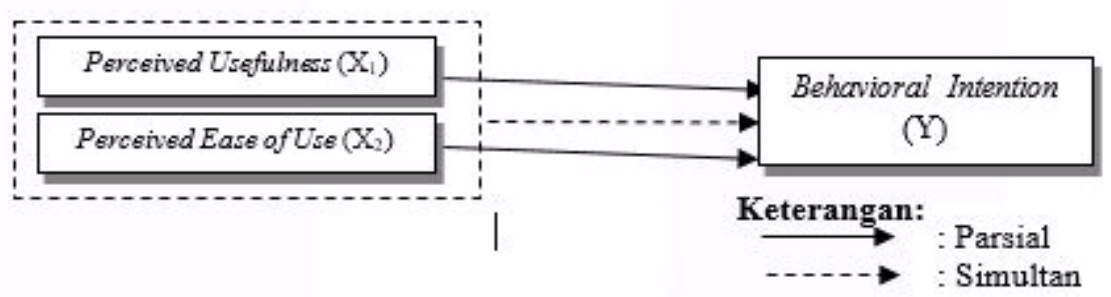

Sumber : Diadopsi dari TAM (Davis, 1989)

Gambar 1. Model Kerangka Pemikiran 


\section{HASIL PENELITIAN DAN PEMBAHASAN}

Tujuan dari penelitian ini yaitu untuk menguji pengaruh variabel independen berupa Perceived Usefulness dan Perceived Ease of Use dengan variabel dependen yaitu Behavioral Intention pada Pengguna Instant Messaging LINE di Indonesia.

\section{Analisis Deskriptif}

Analisis deskriptif dilakukan dengan membagi skor total dengan skor perolehan pada jawaban kuesioner. Tanggapan responden secara keseluruhan terhadap variabel Perceived Usefulness $\left(\mathrm{X}_{1}\right)$ adalah 13.647, sedangkan tanggapan secara keseluruhan yang diharapkan adalah 5 (nilai tertinggi) $x \quad 9$ (jumlah pertanyaan) $\mathrm{x} 400$ (jumlah responden $)=18.000$ menghasilkan presentase $75,81 \%$. Maka variabel Perceived Usefulness berada pada kategori "tinggi". Tanggapan responden secara keseluruhan terhadap variabel Perceived Ease of Use $\left(\mathrm{X}_{1}\right)$ adalah 8.143, sedangkan tanggapan secara keseluruhan yang diharapkan adalah 5 (nilai tertinggi) x 5 (jumlah pertanyaan) x 400 (jumlah responden) $=10.000$ menghasilkan presentase $81,43 \%$. Maka variabel Perceived Ease of Use berada pada kategori "tinggi". Tanggapan responden secara keseluruhan terhadap variabel Behavioral Intention $\left(\mathrm{X}_{1}\right)$ adalah 4.771, sedangkan tanggapan secara keseluruhan yang diharapkan adalah 5(nilai tertinggi) $\mathrm{x} 3$ (jumlah pertanyaan) $\mathrm{x} 400$ (jumlah responden) $=6.000$ menghasilkan presentase 79,52\%. Maka variabel Behaavioral Intention` berada pada kategori "tinggi".

\section{Analisis Regresi Linear Berganda}

Berdasarkan pengolahan data tabel 1 maka dapat diperoleh pesamaan regresi sebagai berikut:

$$
Y=0,72+0,401 X_{1}+0,551 X_{2}
$$

Persamaan di atas dapat diartikan sebagai berikut: a) Nilai konstanta menunjukkan besaran 0,72 yang artinya tanpa adanya pengaruh variabel $X_{1}$, dan $X_{2}$ atau seluruh variabel tersebut bernilai 0 , maka nilai dari $\mathrm{Y}$ adalah 0,72 . b) Nilai koefisien regresi $X_{1}$ bersifat positif sebesar 0,401 , artinya variabel $X_{1}$ memiliki hubungan searah dengan $\mathrm{Y}$ dan setiap pertambahan satu satuan Perceived Usefulness $\left(\mathrm{X}_{1}\right)$ akan berpengaruh terhadap meningkatnya Behavioral Intention (Y) sebesar 0,401. c) Nilai koefisien regresi $\mathrm{X}_{2}$ bersifat positif sebesar 0,551 , artinya variabel $X_{2}$ memiliki hubungan searah dengan $\mathrm{Y}$ dan setiap pertambahan satu satuan Perceived Ease of Use $\left(\mathrm{X}_{2}\right)$ akan berpengaruh terhadap meningkatnya Behavioral Intention $(\mathrm{Y})$ sebesar 0,551.

Tabel 1: Hasil Persamaan Regresi

\begin{tabular}{ccccccc}
\hline \multirow{2}{*}{ Model } & \multicolumn{2}{c}{$\begin{array}{c}\text { Unstandardized } \\
\text { Coefficients }\end{array}$} & $\begin{array}{c}\text { Standardized } \\
\text { Coefficients }\end{array}$ & $\mathrm{T}$ & Sig. \\
\hline & \multicolumn{1}{c}{$\mathrm{B}$} & Std. Error & Beta & & \\
\hline & (Constant) & .072 & .163 & & .442 & .656 \\
1 & $\mathrm{X} 1$ & .401 & .058 & .299 & 6.886 & .000 \\
& $\mathrm{X} 2$ & .551 & .046 & .519 & 11.962 & .000 \\
\hline
\end{tabular}

a. Dependent Variable: Y

Sumber : Hasil Output SPSS 20

\section{Pengujian Hipotesis Secara Simultan}

Tabel 2: Pengujian Hipotesis Simultan

ANOVA $^{\text {a }}$

\begin{tabular}{|c|c|c|c|c|c|c|}
\hline & Model & Sum of Squeres & df & $\begin{array}{c}\text { Mean } \\
\text { Square }\end{array}$ & $\mathrm{F}$ & Sig. \\
\hline \multirow{3}{*}{1} & Regression & 145,764 & 2 & & 249,619 & .000 \\
\hline & Residual & 115,913 & 397 & 72.882 & & \\
\hline & Total & 261,667 & 399 & .292 & & \\
\hline
\end{tabular}

a. Dependent Variable: $\mathrm{Y}$

b. Preditors: (Constant), X2, X1

Sumber : Hasil Output SPSS 20 
Berdasarkan hasil uji hipotesis secara simultan (uji F) pada tabel 4.3, didapat nilai $F_{\text {hitung }}>F_{\text {tabel }}$ yaitu $(249,619>3,02)$ dan tingkat signifikansinya $0,000<0,05$. Hal ini menandakan bahwa dua variabel bebas yakni perceived usefulness $\left(\mathrm{X}_{1}\right)$ dan perceived ease of use $\left(\mathrm{X}_{2}\right)$ secara bersama-sama mempengaruhi behavioral intention $(\mathrm{Y})$ pada pengguna instant messaging LINE di Indonesia. Sedangkan besarnya pengaruh variabel bebas yaitu, Perceived Usefulness $\left(\mathrm{X}_{1}\right)$ dan Perceived Ease of Use $\left(\mathrm{X}_{2}\right)$ terhadap variabel terikat yaitu, Behavioral Intention (Y) dapat dilihat dalam nilai koefisien determinasi $\left(\mathrm{R}^{2}\right)$ pada tabel 3 .

Hasil penelitian ini sejalan dengan penelitian, Imandari (2013), Setiawan (2015), Wang, Hsu, dan Fang (2005) yang menyatakan bahawa Perceived Usefulness dan Perceived Ease of use mempunyai pengaruh terhadap Behavioral Intention. Hal yang sama diungkap Fakhrunnisa (2013) dimana Perceived Usefulness dan Perceived Ease of Use keduanya mempunyai pengaruh terhadap Behavioral Intention.

Tabel 3 menunjukan bahwa nilai $R$ Square $=0,557$ berarti hubungan antara variabel bebasperceived usefulness dan perceived ease of use terhadap variabel terikat behavioral intention sebesar $55,7 \%$. Nilai $R$ Square $=0,557$ berarti $55,7 \%$ variabel behavioral intention dapat dijelaskan oleh variabel perceived usefulness dan perceived ease of usesedangkan sisanya 44,3\% dijelaskan oleh variabel lain yang tidak diteliti dalam penelitian ini seperti:fasilitas fitur, fitur tambahan, tingkat kualitas produk dan desain sesuai kebutuhan pelanggan (Putri dan
Iskandar, 2014), perceived enjoyment (Zhou dan Lu, 2011), network externalities (Strader, 2007).

\section{Pengujian Hipotesis Secara Parsial}

\section{Pengaruh Perceived Usefulness pada Behavioral Intention}

Berdasarkan output SPSS 20 pada tabel 4 . didapatkan hasil yaitu $\mathrm{t}$ hitung $(6,886)>\mathrm{t}$ tabel $(1,97)$ dan tingkat signifikansi $0,000>0,05$. Dari hasil pada tabel 4 maka dapat dinyatakan bahwa secara parsial, variabel Perceived Usefulness berpengaruh secara signifikan terhadap Behavioral Intention pada pengguna instant messaging LINE di Indonesia. Hasil penelitian ini sejalan dengan penelitian Fakhrunnisa (2013); Jannah, Kartika, dan Arif (2015); Setiawan. (2015); Lu, Zhou, dan Wang (2009); Lou, Chau, dan Li, (2005); Sanjaya dan Sugiartha (2005) yang menyatakan bahwa persepsi kemanfaatan (Perceived Usefulness) berpengaruh signifikan terhadap minat berperilaku (Behavioral Intention).

\section{Pengaruh Perceived Ease of Use pada Behavioral Intention}

Berdasarkan output SPSS 20 pada tabel 4 didapatkan hasil yaitu $\mathrm{t}$ hitung $(11,962)>\mathrm{t}$ tabel $(1,97)$. Dari hasil perhitungan secara parsial dapat dinyatakan bahwa variabel Perceived Ease of Use berpengaruh secara signifikan terhadap Behavioral Intentionpada pengguna instant messaging LINE di Indonesia. Hasil penelitian ini konsisten dengan hasil penelitian Setiawan (2015)yang menyatakan bahwa Perceived Ease of Use berpengaruh signifikan terhadap Behavioral Intention to Use.

Tabel 3: Uji Koefisien Determinasi

\begin{tabular}{ccccc}
\hline Model & $\mathrm{R}$ & $\mathrm{R}$ Square & Adjusted R Square & Std. Error of the Estimate \\
\hline 1 & $.746^{\mathrm{a}}$ & .557 & .555 & .540345 \\
\hline
\end{tabular}

a. Preditors: (Constant), X2, X1

b. Dependent Variabel: Y

Sumber : Hasil Output SPSS 20

Tabel 4. Uji Hipotesis Secara Parsial

\begin{tabular}{ccccccc}
\hline & Model & \multicolumn{2}{c}{ Unstandardized Coefficient } & Standardized Coefficient & T & Sig. \\
\hline & & $\mathrm{B}$ & Std. Error & Beta & .659 \\
\hline & (Constant) & .072 & .163 & & .442 & .000 \\
\hline 1 & X1 & .401 & .058 & .299 & 6.886 & .000 \\
\hline & X2 & .551 & .045 & .519 & 11.962 \\
\hline
\end{tabular}

c. Preditors: (Constant), X2, X1

d. Dependent Variabel: Y 


\section{KESIMPULAN DAN SARAN}

\section{Kesimpulan}

Berdasarkan hasil penelitian serta pembahasan yang disertai dengan teori-teori yang mendukung mengenai pengaruh Perceived Usefulness dan Perceived Ease of Use terhadap Behavioral Intention dengan pendekatan Technology Acceptance Model (TAM) pada pengguna Instant Messaging LINE di Indonesia, maka dapat diperoleh kesimpulan sebagai berikut: 1) Perceived Usefulness pada pengguna instant messaging LINE di Indonesia berada pada posisi angka $75,81 \%$. Berdasarkan garis kontinum variabel Perceived Usefulness berada pada kategori tinggi, artinya responden telah merasakan manfaat yang diberikan oleh instant messaging LINE. Item yang memiliki nilai tertinggi dalam variabel Perceived Usefulness yaitu "Sticker yang memudahkan dalam mengungkapkan ekspresi" dengan bobot $82,4 \%$ dan yang memiliki nilai terendah yaitu pada item" fitur LINE games memberikan hiburan" dengan bobot 62,6\%. 2) Perceived Ease of Use pada pengguna instant messaging LINE di Indonesia berada pada posisi angka $81,43 \%$. Berdasarkan garis kontinum variabel Perceived Ease of Use berada pada kategori tinggi. Item yang memiliki nilai tertinggi dalam variabel Perceived Ease of Use"Mudah dalam belajar mengoperasikan LINE" dengan bobot $83,85 \%$ dan yang memiliki nilai terendah yaitu pada item "mudah dalam mengendalikan fiturfitur LINE" dengan bobot 79,95\%. 3) Behavioral Intention pada pengguna instant messaging LINE di Indonesia berada pada posisi angka $79,52 \%$. Berdasarkan garis kontinum variabel Behavioral Intention berada pada kategori tinggi. Item yang memiliki tertinggi dalam variabel Behavioral Intention yaitu item"saya bermaksud menggunakan LINE dalam waktu dekat" dengan bobot $80,9 \%$ dan yang memiliki nilai terendah yaitu "sayaberniat menggunakan LINE dalam aktivitas sehari-hari secara terus-menerus" dengan bobot 77,6\% . 4) Dari hasil analisis data dapat diketahui bahwa variabel Perceived Usefulness berpengaruh signifikan terhadap Behavioral Intention pada pengguna instant messaging LINE di Indonesia. 5) Berdasarkan analisis data dapat diketahui bahwa variabel Perceived Ease of Use berpengaruh signifikan terhadap Behavioral Intention pada pengguna instant messaging LINE di Indonesia. 6) Data dari hasil penelitian menunjukan bahwa Perceived Usefulness $\left(\mathrm{X}_{1}\right)$ dan Perceived Ease of Use $\left(\mathrm{X}_{2}\right)$ secara bersama-sama mempengaruhi Behavioral Intention (Y) pada pengguna instant messaging LINE di Indonesia. Besarnya pengaruh variabel Perceived Usefulness dan Perceived Ease of Use terhadap Behavioral Intention sebesar $55,7 \%$ sedangkan sisanya $44,3 \%$ dijelaskan oleh variabel lain yang tidak diteliti dalam penelitian ini seperti: fasilitas fitur, fitur tambahan, tingkat kualitas produk dan desain sesuai kebutuhan pelanggan (Putri dan Iskandar, 2014), perceived enjoyment (Zhou dan Lu, 2011), network externalities (Strader, 2007).

\section{Saran}

\section{Bagi Perusahaan}

1. Untuk perbaikan, LINE sebaiknya mengeluarkan fitur-fitur yang memang bermanfaat terhadap penggunanya. Penyediaan fitur tambahan LINE dapat disesuaikan dengan fungsi LINE sebagaI media berkirim pesan secara instant. Sehingga fiturfitur yang dikeluarkan LINE dapat bermanfaat dan meningkatkan minat perilaku menggunakan LINE.

2. Untuk para penggunanya, sebaiknya LINE tetap mengutamakan unsur kemudahan dalam mengendalikan fitur tersebut. Sehingga pengguna mudah dalam mengoperasikan fitur-fitur yang disediakan oleh LINE.

3. Untuk perbaikan, LINE sebaiknya lebih menyediakan layanan dan fitur yang membuat penggunanya nyaman dan semakin meningkatkan intensitas penggunaan LINE. Hal tersebut dapat dilakukan dengan menyediakan layanan dan fitur yang benar-benar manfaat dan memiliki kemudahan dalam penggunaannya, sehingga mengeluarkan layanan dan fitur yang sesuai kebutuhan pengguna.

\section{Aspek Praktis}

1. Bagi penelitian selanjutnya, disarankan dapat menggunakan instant messaging BBM dan WhatsApp dikarenakan masuk dalam kategori 10 Aplikasi yang paling banyak di pilih di Indonesia (nielsen.com) 
2. Penelitian selanjutnya, disarankan dapat menggunakan variabel lainnya yang tidak diteliti dalam penelitian ini seperti: fasilitas fitur, fitur tambahan, tingkat kualitas produk, dan desain sesuai kebutuhan pelanggan (Putri dan Iskandar, 2014), perceived enjoyment (Zhou dan Lu, 2011), network externalities (Strader, 2007), serta dapat menggunakan hasil penelitian ini sebagai acuan untuk mengembangkan penelitian lainnya.

\section{DAFTAR PUSTAKA}

Agarwal, R. and Karahanna, E. 2000. Time flies when you're having fun: cognitive absorption and beliefs about information technology usage. MIS Quarterly. (24)4. 665-694.

Ajzen, Icek. 1991. The theory of planned behavior. Organizational Behavior and Human Decision Processes. 50. 179211.

Bhaskoro, Avi Tejo. 2014. LINE dalam Sejumlah Angka. From http://dailysocial.id. Diakses tanggal 11 Oktober 2015.

Chau, P.Y.K., Cole, M., Massey, A., MontoyaWeiss, M. and O'Keefe, R.M. 2002. Cultural Differences in Consumer's Online Behavior. Communications of the ACM. (45)10. 138-143.

Choi, Y. K., Kim, J., and McMillan, S. J. 2009. Motivators for the intention to use mobile tv: A comparison of South Korean males and females. International Journal of Advertising. 28. 147-167.

Cumming, J.N., Butler, B. and Kraut, R. 2002. The quality of online social relationships. Communications of the ACM. 45(7). 103-108.

Davis, F.D. 1989. Perceived usefulness, perceived ease of use, and user acceptance of information technology. MIS Quarterly. 13(3). 319-340.

Davis, F.D. 1993. User acceptance of information technology: system characteristics, user perceptions and behavioral impacts. International
Journal Management Machine Studies. 38. 475-487.

Fakhrunnisa, A. 2013. Pengaruh persepsi kemanfaatan dan sikap pengguna terhadap minat menggunakan internet (Studi pada tenaga kependidikan di Fakultas Ilmu Administrasi Universitas Brawijaya Malang). Jurnal Administrasi Bisnis. 5(2).

Fishbein, M and Ajzen I. 1975. Beliefs, Attitude, Intention and Behavior. New Yok. Addison-Wesley Publishing Company.

Gunelius, S. 2011. Content Marketing for Dummies. John Wiley \& Sons.

Imandari, F. 2013. Pengaruh persepsi kemanfaatan dan persepsi kemudahan terhadap minat berperilaku dalam penggunaan e-learning (Studi pada dosen Fakultas Ilmu Administrasi Universitas Brawijaya). Jurnal Administrasi Bisnis. 3(2).

Jannah, G. N., Kartika, K., dan Arif, A. 2015. Analisis faktor yang mempengaruhi penerimaan unej digital repository dengan menggunakan technology acceptance model (TAM).e-Journal Ekonomi Bisnis dan Akuntansi. 2(1). 512.

Lewis, C., \& Fabos, B. 2005. Instant messaging, literacies, and social identities. Reading Research Quarterly. 40(4). 470-501.

Line Corporation. Logo LINE. 2015. From http://linecorp.com/en/ . Diakses tanggal 2 Oktober 2015).

Lou, H., Chau, P. Y., dan Li, D. 2005. Understanding individual adoption of instant messaging: An empirical investigation. Journal of the Association for Information Systems. 6(4). 5.

Lu, Y., Zhou, T., dan Wang, B. 2009. Exploring Chinese users' acceptance of instant messaging using the theory of planned behavior, the technology acceptance model, and the flow theory. Computers in Human Behavior. 25(1). 29-3. 
Nysveen, H.; Pedersen, P. E.; dan Thorbjørnsen, H. 2005a. Explaining intention to use mobile chat services: Moderating effects of gender. Journal of Consumer Marketing. 22(5). 247256.

Nysveen, H.; Pedersen, P.; dan Thorbjornsen, H. 2005b. Intentions to use mobile services: Antecedents and cross-service comparisons. Journal of Academy of Marketing Science. 33(3). 330-346.

Peslak, Alan R. (2008). An empirical study of instant messaging behavior based on the technology assessment model (TAM). Journal Issues in Information System. IX(2).

Putri, Noventi Ersa dan Iskandar, Dadang. 2014. Analisis preferensi konsumen dalam penggunaan social messenger di kota Bandung tahun 2014 (Studi kasus : LINE, KakaoTalk, WeChat, WhatsApp). Jurnal Manajemen Indonesia. 114(2).

Rasul, Juharis. 2008. Teknologi, Informasi dan Telekomunikasi. Bogor: Quadra.

Riset Puskakom dan APJII. 2015. Profil Pengguna Internet Indonesia 2014. Jakarta : Puskakom UI dan APJII.

Rowley, J. 2008. Understanding digital content marketing. Journal of Marketing Management. 24(5-6), 517-540.

Rustiana. 2006. Studi Model Penerimaan Tehnologi (Technology Acceptance Model Novice Accountant). Kinerja, 10(1).

Sanjaya, I., dan Sugiartha, P. 2005. Pengaruh Rasa Manfaat dan Kemudahan Terhadap Minat Berperilaku (Behavioral Intention) Para Mahasiswa dan Mahasiswi dalam Penggunaan Internet. Jurnal Bisnis dan Ekonomi Terakreditasi SK NO. 49/DIKTI/KEPIZOO3, 113.

Setiawan, D. L. B. 2015. Pengaruh Penggunaan E-Learning terhadap Kinerja Dosen dalam Kegiatan Mengajar (Studi pada Dosen Fakultas Ilmu Administrasi Universitas Brawijaya). Jurnal Administrasi Bisnis. 19(1).

Strader, T. J., Ramaswami, S. N., dan Houle, P. A. 2007. Perceived network externalities and communication technology acceptance. European Journal of Information Systems. 16(1). 54-65.

Survey Nielsen. Aplikasi Terkemuka Smartphone Pilihan di Asia Tenggara. 2015. From http://www.nielsen.com/apac/en/top10s .html. Diakses tanggal 11 Oktober 2015.

Teo, T. S. H.; Lim, V. K. G.: and Lai, R. Y. C. 1999. Intrinsic and extrinsic motivation in internet usage. The Internet Journal of Management Science, 27, 25-37.

Venkatesh, V., Morris, M. G., Davis, G. B., dan Davis, F. D. 2003. User acceptance of information technology: Toward a unified view. MIS quarterly. 425-478.

Vijayasarathy, Leo R. 2003. Predicting consumer intentions to use on-line shopping: The case for an augmented technology acceptance model. Journal of Information dan Management. 41. 747-762.

Wang, C.C.; Hsu, Y.H.; and Fang, W. 2005. Acceptance to technology with network externalities: An empirical study of internet instant messaging services. Journal of Information Technology Theory and Application. 6(4). 15-28.

Zhou, T., dan Lu, Y. 2011. Examining mobile instant messaging user loyalty from the perspectives of network externalities and flow experience. Computers in Human Behavior. 27(2). 883-889.

Zuliarso Eri dan Henry Februariyanti. 2013. Pemanfaatan instant messaging untuk aplikasi layanan akademik. Jurnal Teknologi Informasi Dinamik. 18(2). 112-121. 